\title{
Erratum to: Effect of increased seawater temperature on biomass, growth, and maturation of Saccharina japonica near its southern limit in northern Japan
}

\author{
$\mathrm{Xu} \mathrm{Gao}{ }^{1} \cdot$ Hikaru Endo $^{1} \cdot$ Yukio Agatsuma $^{1}$
}

Published online: 1 August 2015

(C) Springer Science+Business Media Dordrecht 2015

Erratum to: J Appl Phycol (2015) 27:1263-1270

DOI 10.1007/s10811-014-0417-0

The corresponding author has forgotten to include the reference (Ogasawara et al. 2011) providing the data for part Fig. 4. The following corrections must be done in order to correct the missing information in the published article.

1. In Page 1265, (results part; standing biomass), "The seasonal changes in standing biomass of algal populations in 2005 and 2006 are shown in Fig. 4." should be changed to "The seasonal changes in standing biomass of algal populations in 2005 and 2006 are shown in Fig. 4 (Ogasawara et al. 2011)."
2. Figure 4 caption should read:

Fig. 4 Seasonal changes in standing biomass ( $\mathrm{g}$ fresh weight $625 \mathrm{~cm}^{-2}$ ) of the populations of $S$. japonica (black bar charts), U. pinnatifida (gray bar charts), and other algae (white bar charts) from February 2005 to November 2006 (Ogasawara et al. 2011)

3. Below is the complete bibliographic information for the missing reference which should have been added in the References.

Ogasawara M, Matsui T, Agatsuma Y (2011) Growth and Rapid Gonad Recovery of the Sea Urchin Hemicentrotus pulcherrimus After Spawning in an Undaria pinnatifida and Saccharina japonica Kelp Bed. J Shell Res 30 (1):159-166.

The online version of the original article can be found at http://dx.doi.org/ 10.1007/s10811-014-0417-0.

Xu Gao

algaepanda69@163.com

Laboratory of Marine Plant Ecology, Graduate School of Agricultural Science, Tohoku University, Sendai, Miyagi Prefecture 981-8555, Japan 